\title{
Potencial fitotóxico de extratos foliares de Aloe arborescens Miller (Asphodelaceae) produzidos em diferentes épocas do ano
}

\author{
Cynthia Murakami ${ }^{1}$, Fernando Leite Cardoso $^{1}$ e Marco Aurélio Sivero Mayworm ${ }^{1,2}$
}

Recebido em 19/07/2007. Aceito em 26/05/2008

\begin{abstract}
RESUMO - (Análise do potencial fitotóxico de extratos foliares de Aloe arborescens Miller (Asphodelaceae) produzidos em diferentes épocas do ano). Este trabalho visou analisar o potencial fitotóxico de extratos foliares de Aloe arborescens Miller sobre a germinação e crescimento de plântulas de alface (Lactuca sativa L.). Amostras de folhas foram coletadas nas quatro estações climáticas e maceradas em etanol P.A. por 28 dias. Os extratos produzidos foram fracionados em extratos etanólico e clorofórmico e tiveram as concentrações reduzidas a $1 \%$. Os bioensaios de ação fitotóxica foram desenvolvidos em triplicata, sob luz constante e temperatura ambiente. Apenas o extrato clorofórmico de primavera mostrou forte atividade fitotóxica sobre a germinação das sementes de alface (16,67\%). Todos os extratos reduziram significativamente a primeira contagem, índice de velocidade germinação (IVG) e o crescimento do eixo hipocótiloradicular (EHR) das plântulas de alface, porém os extratos clorofórmicos mostraram maior atividade fitotóxica, gerando alterações morfológicas mais intensas sobre as plântulas de alface e apresentaram maiores teores de compostos fenólicos. Apesar de todos os extratos clorofórmicos inibirem fortemente o crescimento das folhas cotiledonares das plântulas de alface, não se observaram neste último efeito, variações em função dos períodos de coleta.
\end{abstract}

Palavras-chave: alelopatia, Aloe, fitotoxicidade, sazonalidade

\begin{abstract}
Analysis of the phytotoxic potential of Aloe arborescens Miller leaf extracts (Asphodelaceae) produced at different times of the year). This study aimed to analyze seasonal variation in the phytotoxic potential of Aloe arborescens Miller leaf extract on lettuce (Lactuca sativa L.) germination and growth. Leaf samples were collected in the four seasons and were macerated in ethanol P.A. for 28 days. The extracts were fractionated into solutions made with ethanol and chloroform, and concentrations were reduced to $1 \%$. Phytotoxic activity bioassays were carried out in triplicate, under constant light and ambient temperature. Only the spring chloroform extract showed strong phytotoxic activity on lettuce seed germination (16.67\%). All extracts significantly reduced the first count, germination velocity index (GVI) and growth of the hipocotyl-root axis (HRA) of the lettuce plants. However, the chloroform extracts showed greater phytotoxic activity, producing more intense morphology alterations on lettuce plants and showed greater content of phenolic compounds.
\end{abstract}

Key words: allelopathy, Aloe, phytotoxicity, seasonality

\section{Introdução}

Aloe arborescens, conhecida popularmente como babosa, erva babosa ou caraguatá de jardim, apresenta folhas grandes e suculentas, com acúleos nas margens. O nome babosa é dado também a várias outras espécies nativas de regiões quentes e áridas da África Oriental e Meridional (Costa 2002), tais como Aloe vera L., A. succotrina Lamk., A. spicata L. e A. ferox Mill. (Pio Corrêa 1926).

Em Aloe arborescens, foram reconhecidos metabólitos como aloína Ae B, aloe-emodina, 10-hidroxialoina, aloenina (Okamura et al. 1996; Park et al. 1998), aloesina A e B, microdontina A e B, saponinas (Viljoen et al. 2001), homonataloína (Beaumont et al. 1984), ácido succínico, lactato de magnésio (Hirata \& Suga 1977), isobarbaloína, emodina, ácido aloético (Saito 1993; Beppu et al. 2004), compostos aromáticos (Umano et al. 1999), aloeresina (Gutterman \& Chauser-Volfson 2000) e mucopolissacarídeos (Yagi et al. 1986; Stevens 1999). As antraquinonas, aloína e emodina, obtidas a partir da resina localizada em canais abaixo da epiderme das folhas, possuem atividades catártica e laxativa em animais e no homem (Stevens 1999). Extratos e compostos isolados de $A$. arborescens mostraram atividades antifúngica, antiinflamatória, hipoglicemiante, hemaglutinante, atividade mitogênica para linfócitos e atividade protetora contra raios-X (Fujita et al. 1978; Ali et al. 1999; Yamamoto et al. 1991; Beppu et al. 1993; Saito 1993; Sato et al. 1990), porém não foram encontrados

\footnotetext{
1 Universidade de Santo Amaro (UNISA), Faculdade de Biologia, Laboratório de Fitoquímica, Rua Prof. Enéas de Siqueira Neto 340, Jardim das Imbuias, 04829-300 São Paulo, SP, Brasil

2 Autor para correspondência: masmayworm@ig.com.br
} 
trabalhos sobre atividade alelopática ou fitotóxica.

A alelopatia pode ser definida como uma interferência positiva ou negativa de compostos do metabolismo secundário produzidos por uma planta e lançados no meio (Ferreira 2004). Vários grupos de substâncias tais como ácidos graxos de cadeia longa, fenóis simples, terpenóides, cumarinas, alcalóides, taninos, óleos essenciais, quinonas, saponinas e flavonóides apresentam moléculas com potencial alelopático (Whitaker \& Feeny 1971; Rice 1984; Almeida 1988; Alves \& Santos 2002) e sua composição pode ser alterada quantitativa e qualitativamente por fatores bióticos (ritmo circadiano, ataque por herbívoros e patógenos, idade do órgão ou do indivíduo) e por fatores abióticos (disponibilidade hídrica, temperatura, radiação UV, altitude, composição do solo, composição atmosférica, etc.) (Tang et al. 1995; Alves et al. 2002; Gobbo Neto \& Lopes 2007).

Santos et al. (2006) observaram maiores teores de compostos fenólicos em Stryphnodendron adstringens (Mart.) Coville e S. polyphyllum Mart. (barbatimão) nos períodos mais úmidos do ano. Segundo Waterman \& Mole (1994), o conteúdo fenólico nas plantas de sol é relativamente maior em relação às de sombra. Plantas de Nicotiana tabacum L. (tabaco) quando expostas a baixas temperaturas apresentam diminuição nos teores de escopolamina e aumento dos teores de ácido clorogênico (Rice 1984). O conteúdo total dos taninos em folhas de Quercus robur L. (carvalho) aumenta, em massa seca, de $0,7 \%$ na primavera para $5,5 \%$ no outono (Feeny 1970). Em Calluna vulgaris (L.) Hull, a composição e a concentração de compostos fenólicos variam consideravelmente com a sazonalidade, aumentando a diversidade e teor desses compostos no verão em relação ao inverno (Jalal et al. 1982). Em Hypericum perforatum L. os teores de hipericina variaram de $100 \mathrm{ppm}$ no inverno até 3000 ppm no verão (Southwell \& Bourke 2001). Em muitas espécies, as antraquinonas reduzidas (antranóis) predominam particularmente durante o inverno, enquanto antraquinonas oxidadas encontram-se em maior teor durante o verão (Costa 2002). A concentração de juglona, uma naftoquinona, liberada no solo pelas raízes de Juglans nigra L. é maior na primavera, diminuindo no verão (De Scisciolo et al. 1990). Uma vez que as atividades biológicas desenvolvidas por extratos vegetais são geradas pela sua composição química, a qual pode ser alterada por fatores bióticos e abióticos, alterações na intensidade das atividades biológicas poderão ocorrer de acordo com a época de coleta, propiciando assim um amplo campo de estudo, incluindo controle de plantas daninhas (Alves et al. 2002).

Em Aloe arborescens, os teores de antraquinonas variam ao longo das estações do ano, porém os dados de literatura são ainda conflitantes (Koshioka et al. 1982; Park et al. 1998; Beppu et al. 2004). Neste sentido, foi estudado o potencial fitotóxico de extratos foliares, obtidos em diferentes épocas de coleta, de Aloe arborescens sobre a germinação e crescimento de plântulas de Lactuca sativa (alface).

\section{Material e métodos}

Folhas adultas $\left(10^{\mathrm{a}}\right.$ a $15^{\mathrm{a}}$ folha de cada ramo) de um indivíduo de Aloe arborescens foram coletadas em uma propriedade particular, no bairro de Chácara Santo Amaro (2346'57'’S e 4643'27’W), São Paulo, em área livre da presença de agrotóxicos ou outros insumos agrícolas, durante as quatro estações climáticas (inverno - 18/08/2004, primavera - 17/11/2004, verão - 16/02/2005 e outono - 18/05/2005), e processadas no mesmo dia da coleta. Amostras testemunhas foram herborizadas e depositadas no Herbário da Universidade de Santo Amaro (C. Murakami, 002). As amostras de folhas foram fragmentadas e submersas em etanol $99,5^{\circ} \mathrm{GL}$, agitadas diariamente e o solvente trocado a cada sete dias, perfazendo um total de 28 dias de extração. Após a terceira extração $\left(21^{\circ}\right.$ dia), o material foi triturado em liquidificador e submerso novamente em etanol $99,5^{\circ} \mathrm{GL}$. As extrações foram feitas à temperatura ambiente e protegidas da luz, a fim de evitar a foto-oxidação de compostos. Os filtrados obtidos foram reunidos, constituindo os extratos etanólicos brutos, os quais foram concentrados sob pressão reduzida, em rotaevaporador, a $45{ }^{\circ} \mathrm{C}$ (Bernard et al. 1995).

Os extratos etanólicos brutos foram lavados com clorofórmio (três vezes), na proporção de 1:1, a fim de se separarem os compostos mais apolares (extrato clorofórmico) e os mais polares (extrato etanólico). Os volumes dos extratos foram reduzidos em rotaevaporador e as concentrações acertadas a 1\%. Para determinar o rendimento de massa seca das amostras coletadas, foram selecionados, em cada coleta, oito fragmentos de folhas frescas de mesmo tamanho, em triplicata, pesados imediatamente em balança analítica e acondicionados em estufa, a $100{ }^{\circ} \mathrm{C}$, durante 24 horas. Os fragmentos secos foram mantidos em dessecador contendo sílica indicadora de umidade, fechado a vácuo, até massa constante.

Os testes de ação fitotóxica foram desenvolvidos em triplicatas. Em discos de papel de filtro com $9 \mathrm{~cm}$ de diâmetro, foram depositados $4 \mathrm{ml}$ de cada extrato, seguindo um movimento em espiral, com o objetivo de se obter uma distribuição uniforme. Em outros discos de mesmo diâmetro foram depositados, separadamente, os mesmos volumes de etanol $99,5^{\circ}$ GL e clorofórmio, constituindo os respectivos controles. Após prévia 
secagem, os discos de papel foram transferidos para as placas de Petri e deixados em dessecador a vácuo, durante 24 horas, para eliminação total dos solventes. Após esse período, cada placa recebeu $4 \mathrm{ml}$ de água destilada e foi mantida fechada, em repouso, por duas horas para melhor contato dos componentes do extrato com a água. Em cada placa, foram depositados 20 aquênios de alface, cultivar 'Marisa AG-216'. As placas foram vedadas com filme de PVC, para reduzir a perda de água por evaporação, e mantidas sob iluminação constante e temperatura ambiente, por seis dias. Sobre a germinação, foram avaliados a primeira contagem (24 horas após a semeadura), a germinação total ( $6^{\circ}$ dia) e o índice de velocidade de germinação (IVG), calculado segundo Maguire (1962). Foram consideradas germinadas as sementes que emitiram radículas com mais de $3 \mathrm{~mm}$. As análises de crescimento do eixo hipocótiloradicular (EHR) e das folhas cotiledonares das plântulas de alface foram avaliadas no $6^{\circ}$ dia.

Dosagens de fenóis totais dos extratos etanólicos e clorofórmicos foram feitas em duplicata, utilizando balões volumétricos de $50 \mathrm{ml}$, aos quais foram adicionados $35 \mathrm{ml}$ de água deionizada, $0,3 \mathrm{ml}$ de extrato etanólico ou $0,2 \mathrm{ml}$ de extrato clorofórmico, 2,0 $\mathrm{ml}$ de Follin Ciocauteau, $5,0 \mathrm{ml}$ de solução saturada de carbonato de sódio $\left(\mathrm{NaCO}_{3}\right)$ e água deionizada até completar o volume de $50 \mathrm{ml}$. Os frascos foram agitados e, após duas horas, procederam-se às leituras em espectrofotômetro, medindo a absorbância em $760 \mathrm{~nm}$, utilizando-se como padrão, ácido tânico (100 mg/l) (Waterman \& Mole, 1994). Dosagens de açúcares totais foram realizadas em duplicata, em tubos de ensaio, utilizando-se $20 \mu \mathrm{l}$ das amostras, 1,0 ml de água destilada, 0,5 $\mathrm{ml}$ de fenol (5\%) e 2,5 $\mathrm{ml}$ de ácido sulfúrico P.A. As leituras foram feitas em espectrofotômetro, medindo-se a absorbância em $490 \mathrm{~nm}$ e utilizando-se como padrão solução de glicose $(100 \mu \mathrm{g} / \mathrm{ml})$ (Dubois et al. 1956).

Dados de precipitação e temperatura média durante o período de realização do experimento, foram obtidos junto a estação E3-035 do IAG/USP, localizada no bairro da Água Funda (2339'S, 46³6'W), estação de medição mais próxima da área onde a espécie estudada se encontrava (IAG/USP 2005).

O delineamento experimental para todos os bioensaios foi inteiramente casualizado, com três repetições de 20 aquênios de alface. As médias dos dados foram comparadas pelo teste de Tukey a 5\% de probabilidade. Utilizou-se o software Sodek para a análise de dados.

\section{Resultados e discussão}

Observou-se maior porcentagem de massa seca total nas folhas coletadas no inverno (Tab. 1). O período que antecedeu a coleta de inverno apresentou as menores temperaturas e os menores valores de precipitação (Tab. 2), indicando que essas condições climáticas podem ter alterado o metabolismo da espécie estudada. Os rendimentos dos extratos etanólicos semelhantes entre as coletas de primavera, verão e outono, e menor na coleta de inverno podem ser conseqüência do fato de o aumento de massa seca nas folhas de inverno ter sido gerado principalmente por acúmulo de compostos insolúveis, como componentes de paredes celulares.

Os extratos clorofórmicos apresentaram atividade fitotóxica geralmente maior em relação aos etanólicos. Entre os oito extratos testados, apenas o extrato clorofórmico de primavera teve forte atividade fitotóxica sobre a taxa final de germinação das sementes de alface (Tab. 3). Resultados semelhantes foram encontrados por Lin et al. (2004); Oliveira et al. (2004) e MaraschinSilva \& Aqüila (2006). Todos os extratos reduziram significativamente os valores de primeira contagem e conseqüentemente os valores de índice de velocidade de germinação (IVG) em relação aos respectivos controles (Tab. 3). Os menores IVG foram observados nos extratos clorofórmicos de inverno e de primavera. Sobre os extratos etanólicos, as sementes de alface apresentaram IVG significativamente diferentes dos

Tabela 1. Massas fresca e massa seca das amostras de folhas de Aloe arborescens Miller e rendimento dos extratos etanólicos e clorofórmicos de cada período de coleta.

\begin{tabular}{|c|c|c|c|c|c|c|c|}
\hline \multirow{4}{*}{ Período de coleta } & \multicolumn{3}{|c|}{ Amostras de folhas } & \multicolumn{4}{|c|}{ Rendimento (P.S.) } \\
\hline & \multirow{3}{*}{$\begin{array}{c}\text { Massa fresca } \\
\text { total } \\
(\mathrm{g})\end{array}$} & \multirow{2}{*}{\multicolumn{2}{|c|}{$\begin{array}{c}\text { Massa seca } \\
\text { total }\end{array}$}} & \multicolumn{4}{|c|}{ Extrato } \\
\hline & & & & \multicolumn{2}{|c|}{ Clorofórmico } & \multicolumn{2}{|c|}{ Etanólico } \\
\hline & & $(\%)$ & (g) & (g) & $(\%)$ & (g) & $(\%)$ \\
\hline Inverno & 1804,82 & $249,18 \mathrm{a}$ & $13,81 \mathrm{a}$ & 3,37 & 1,35 & 37,18 & 14,92 \\
\hline Primavera & 1692,16 & $169,25 b$ & $10,08 b$ & 2,61 & 1,54 & 37,23 & 21,99 \\
\hline Verão & 1916,85 & $181,99 b$ & $9,54 b$ & 2,60 & 1,43 & 41,73 & 22,93 \\
\hline Outono & 1356,07 & $123,69 b$ & $9,12 b$ & 2,04 & 1,65 & 27,95 & 22,60 \\
\hline
\end{tabular}


controles, com exceção do extrato produzido na primavera. Extratos de Mimosa caesalpiniifolia Benth. não influenciaram a porcentagem de germinação, porém reduziram a velocidade de germinação de sementes de Tabebuia alba (Cham.) Sandw (Pinã-Rodrigues \& Lopes 2001). De fato, muitas vezes o efeito alelopático não se dá sobre a porcentagem final de germinação, mas, por exemplo, sobre o IVG (Ferreira 2004).

Tabela 2. Índice pluviométrico mensal e acumulado e temperatura média mensal na cidade de São Paulo, Brasil, no período anterior à coleta de amostras de folhas de Aloe arborescens Miller.

\begin{tabular}{lcccc}
\hline Meses & Coleta & $\begin{array}{c}\text { Precipitação } \\
\text { mensal } \\
(\mathrm{mm})\end{array}$ & $\begin{array}{c}\text { Precipitação } \\
\text { acumulada } \\
(\mathrm{mm})\end{array}$ & $\begin{array}{c}\text { Temperatura } \\
\text { média mensal } \\
\left({ }^{\circ} \mathrm{C}\right)\end{array}$ \\
\hline jun./2004 & & 70,5 & & 16,0 \\
jul./2004 & & 102,4 & & 15,3 \\
ago./2004 & inverno & 2,8 & 175,7 & 16,3 \\
set./2004 & & 23,5 & & 19,9 \\
out./2004 & & 110,1 & & 18,6 \\
nov./2004 & primavera & 289,6 & 423,2 & 20,2 \\
dez./2004 & & 223,9 & & 20,6 \\
jan./2005 & & 385,8 & & 22,0 \\
fev./2005 & verão & 68,4 & 678,1 & 21,4 \\
mar./2005 & & 103,5 & & 21,7 \\
abr./2005 & & 82,6 & & 21,4 \\
mai./2005 & outono & 200,0 & 386,1 & 20,5 \\
\hline
\end{tabular}

Todos os extratos clorofórmicos e etanólicos mostraram ação fitotóxica sobre o crescimento do eixo hipocótilo-radicular (EHR) das plântulas de alface (Tab. 3). As plântulas expostas aos extratos clorofórmicos atingiram $41 \%, 35 \%, 42 \%$ e $39 \%$ do comprimento médio do EHR das plântulas controle, respectivamente no inverno, primavera, verão e outono. As plântulas expostas aos extratos etanólicos atingiram $56 \%, 81 \%, 46 \%$ e $33 \%$, em relação ao comprimento médio do EHR das plântulas controle (Tab. 3), respectivamente no inverno, primavera, verão e outono. Observou-se maior variação sazonal no efeito fitotóxico dos extratos etanólicos sobre o crescimento das plântulas de alface, sendo mais pronunciado nos meses de verão e outono. Por outro lado, o efeito fitotóxico do extratos clorofórmicos mostrou-se pouco influenciado pelo período de coleta, sendo apenas mais expressivo no extrato de primavera (Tab. 3). Os extratos clorofórmicos geraram ainda um maior grau de alterações morfológicas nas radículas, como redução de tamanho, aumento de diâmetro e ausência de tricomas radiculares, características observadas também em outros trabalhos (Medeiros \& Lucchesi 1993; Gatti et al. 2004; Maraschin-Silva \& Aqüila 2006).

Diferentemente do observado neste trabalho, extratos aquosos de $A$. vera estimularam o crescimento da radícula e aumentaram o peso das plântulas de

Tabela 3. Germinação e crescimento de plântulas de Lactuca sativa L. sobre extratos clorofórmicos e etanólicos, produzidos a partir de folhas de Aloe arborescens Miller coletadas nas quatro estações do ano. EHR = eixo hipocótilo-radicular. Médias seguidas de letras distintas nas colunas diferem entre si, a $5 \%$ de probabilidade, pelo teste de Tukey.

\begin{tabular}{|c|c|c|c|c|c|}
\hline \multirow[t]{2}{*}{ Período de coleta } & \multicolumn{2}{|c|}{ Germinação (\%) } & \multirow[t]{2}{*}{ IVG } & \multicolumn{2}{|c|}{ Comprimento (mm) } \\
\hline & Primeira contagem & Final $\left(6 .^{\circ}\right.$ dia $)$ & & EHR & Foliar \\
\hline \multicolumn{6}{|l|}{ Inverno } \\
\hline Extrato clorofórmico & Of & $83,3 b$ & $2,9 \mathrm{~d}$ & $24,9 \mathrm{gh}$ & $*$ \\
\hline Controle clorofórmico & $78,3 \mathrm{a}$ & $91,7 \mathrm{ab}$ & $16,4 \mathrm{a}$ & $61,7 \mathrm{a}$ & $5,2 b c$ \\
\hline Extrato etanólico & $26,7 \mathrm{bcd}$ & $100,0 \mathrm{a}$ & $9,0 \mathrm{bc}$ & $31,4 \mathrm{fg}$ & $6,2 \mathrm{ab}$ \\
\hline Controle etanólico & $83,3 \mathrm{a}$ & $98,3 \mathrm{a}$ & $17,3 \mathrm{a}$ & $60,2 \mathrm{ab}$ & $5,1 \mathrm{bc}$ \\
\hline \multicolumn{6}{|l|}{ Primavera } \\
\hline Extrato clorofórmico & $3,3 \mathrm{ef}$ & $16,7 \mathrm{c}$ & $1,5 \mathrm{~d}$ & $16,3 \mathrm{i}$ & $*$ \\
\hline Controle clorofórmico & $91,7 \mathrm{a}$ & $93,3 \mathrm{ab}$ & $18,4 \mathrm{a}$ & $45,9 \mathrm{~cd}$ & $5,2 b c$ \\
\hline Extrato etanólico & $30,0 \mathrm{bc}$ & $86,7 \mathrm{ab}$ & $17,3 \mathrm{a}$ & $34,2 \mathrm{ef}$ & $6,2 \mathrm{ab}$ \\
\hline Controle etanólico & $93,3 \mathrm{a}$ & $95,0 \mathrm{ab}$ & $18,8 \mathrm{a}$ & $42,2 \mathrm{de}$ & $5,2 b c$ \\
\hline \multicolumn{6}{|l|}{ Verão } \\
\hline Extrato clorofórmico & $11,7 \mathrm{cdef}$ & $93,3 \mathrm{ab}$ & $7,1 \mathrm{c}$ & 22,9hi & $*$ \\
\hline Controle clorofórmico & $88,3 \mathrm{a}$ & $100,0 \mathrm{a}$ & $18,3 \mathrm{a}$ & $55,1 \mathrm{ab}$ & $4,8 \mathrm{c}$ \\
\hline Extrato etanólico & $45,0 \mathrm{~b}$ & $96,7 \mathrm{ab}$ & $11,9 b$ & $24,0 \mathrm{ghi}$ & $5,1 \mathrm{bc}$ \\
\hline Controle etanólico & $95,0 \mathrm{a}$ & $100,0 \mathrm{a}$ & $19,2 \mathrm{a}$ & $52,3 \mathrm{bc}$ & $4,7 \mathrm{c}$ \\
\hline \multicolumn{6}{|l|}{ Outono } \\
\hline Extrato clorofórmico & $10,0 \mathrm{def}$ & $88,3 \mathrm{ab}$ & $7,2 \mathrm{c}$ & $23,6 \mathrm{ghi}$ & * \\
\hline Controle clorofórmico & $81,7 \mathrm{a}$ & $96,7 \mathrm{ab}$ & $17,3 \mathrm{a}$ & $61,1 \mathrm{a}$ & $5,5 \mathrm{abc}$ \\
\hline Extrato etanólico & $21,7 \mathrm{cde}$ & $100,0 \mathrm{a}$ & $9,5 \mathrm{bc}$ & $18,2 \mathrm{hi}$ & $6,6 \mathrm{a}$ \\
\hline Controle etanólico & $83,3 \mathrm{a}$ & $93,3 \mathrm{ab}$ & $17,3 \mathrm{a}$ & $55,9 \mathrm{ab}$ & $5,3 \mathrm{bc}$ \\
\hline
\end{tabular}

* Folhas cotiledonares com tamanho inferior a $3 \mathrm{~mm}$. 
cultivares de alface, rabanete, cebola e arroz (Lin et al. 2004) e não inibiram significativamente o crescimento de plântulas de Ocimum gratissimum L. e O. basilicum L. (Sosa et al. 2003), isso apesar das folhas de Aloe vera e A. arborescens apresentarem muitos compostos em comum (Okamura et al. 1996; Park et al. 1998).

As plântulas desenvolvidas sobre os extratos clorofórmicos apresentaram folhas cotiledonares muito reduzidas, menores que $3 \mathrm{~mm}$, indicando forte ação fitotóxica dos extratos. Por outro lado, os comprimentos médios das folhas cotiledonares das plântulas desenvolvidas sobre os extratos etanólicos foram de $121 \%$ (inverno), $118 \%$ (primavera), $107 \%$ (verão) e $123 \%$ (outono), em relação ao comprimento médio das folhas cotiledonares das plântulas controles (Tab. 3). Geralmente, os compostos com atividade alelopática atuam como inibidores de crescimento (Almeida 1988; Einhellig 1996; Ferreira \& Aqüila 2000); porém, alguns trabalhos mostram que extratos vegetais podem conter substâncias estimulantes de germinação e crescimento de plântulas (Rice 1984; Yokotani-Tomita et al.1998; Lin et al. 2004) ou a variação nos teores de um ou mais compostos pode gerar aumento ou redução do efeito inibidor. Inderjit et al. (1999) observaram que a atividade alelopática de compostos fenólicos presentes em extratos de Verbesina encelioides (Cav.) Benth. \& Hook. f. ex A. Gray é dependente da concentração, podendo promover ou inibir a germinação e desenvolvimento de plântulas de Raphanus sativus L.

$\mathrm{O}$ efeito fitotóxico dos extratos clorofórmicos e etanólicos de A. arborescens foi mais pronunciado sobre o crescimento das plântulas que sobre a germinação das sementes de alface. Peres et al. (2004) observaram resultados semelhantes com extratos de espécies de Pteridaceae, sugerindo como possível explicação, o fato da emergência da radícula ser feita às custas de suas reservas; sendo, por isso, menos influenciada pela presença de compostos inibidores do que o crescimento das plântulas.

Os teores de fenóis totais foram maiores nos extratos clorofórmicos em relação aos extratos etanólicos. Por outro lado, os teores de açúcares foram muito superiores nos extratos etanólicos em relação aos extratos clorofórmicos (Tab. 4). De maneira geral, os extratos clorofórmicos contendo maiores teores de fenóis, geraram maiores reduções nos valores de $1^{\text {a }}$ contagem, nas taxas de IVG e no crescimento do eixo hipocótiloradicular e de folhas cotiledonares de alface, enquanto os extratos etanólicos foram menos agressivos e até estimulantes de crescimento das folhas cotiledonares. Reigosa et al. (1999) também encontraram relação entre as concentrações de compostos fenólicos e estímulo ou inibição da germinação e do crescimento das plântulas.
Além dos compostos fenólicos e polissacarídeos, outros metabólitos como antraquinonas (Beppu et al. 2004) e saponinas (Franco 2001) ocorrem nas folhas de espécies de Aloe. As antraquinonas estão localizadas nos canais resinosos abaixo da epiderme da folha (Stevens 1999), provavelmente mais solubilizadas nos extratos clorofórmicos (Falkenberg 2000). Segundo Rice (1984), as naftoquinonas, antraquinonas e quinonas complexas constituem compostos identificados como agentes alelopáticos. A sorgoleona, uma antraquinona encontrada em exsudatos de raízes de grãos de sorgo (Sorghum sp.), é um potente inibidor do crescimento de plantas e testada sobre a germinação e crescimento de sementes de Lemna minor L., sob concentração de $100 \mu \mathrm{M}$, inibiu o crescimento das plântulas em $73 \%$ (Einhellig \& Souza 1992). Hejl et al. (1993) observaram também efeitos inibitórios de soluções de juglona, uma naftoquinona, a partir de $10 \mathrm{mM}$ sobre o crescimento de L. minor.

$\mathrm{Na}$ natureza, quase todos os casos de inibição alelopática em comunidades de plantas ocorrem por efeito combinado de vários compostos, agindo de maneira aditiva ou sinergística, dependendo das concentrações relativas dos aleloquímicos (Einhellig 1995). A possível presença de antraquinonas típicas de espécies de Aloe em maiores teores nos extratos clorofórmicos, tais como aloína, homonataloína, aloinosídeos A e B e aloenina (Reynolds 1985), poderia a princípio ter contribuído para os efeitos fitotóxicos mais pronunciados gerados por esses extratos em relação aos extratos etanólicos.

Outro aspecto se refere ao fato que a presença de compostos osmoticamente ativos nos extratos, entre os quais açúcares, pode mascarar o seu potencial alelopático (Ferreira 2004). Testes de atividade fitotóxica usando soluções de glicose em diferentes concentrações, com a mesma metodologia utilizada com os extratos de A. arborescens (M.A.S. Mayworm et al., dados não publicados), indicam, a princípio, que os teores de açúcares podem ter influenciado os resultados fitotóxicos

Tabela 4. Teores de fenóis totais $(\mathrm{mg} / \mathrm{ml})$ e açúcares totais $(\mathrm{mg} / \mathrm{ml})$ em extratos clorofórmicos e etanólicos produzidos a partir de folhas de Aloe arborescens Miller coletadas nas quatro estações do ano.

\begin{tabular}{lcccc}
\hline \multirow{2}{*}{$\begin{array}{c}\text { Período de } \\
\text { coleta }\end{array}$} & \multicolumn{2}{c}{ Fenóis totais } & \multicolumn{2}{c}{ Açúcares totais } \\
\cline { 2 - 5 } & $\begin{array}{c}\text { Extrato } \\
\text { clorofórmico }\end{array}$ & $\begin{array}{c}\text { Extrato } \\
\text { etanólico }\end{array}$ & $\begin{array}{c}\text { Extrato } \\
\text { clorofórmico }\end{array}$ & $\begin{array}{c}\text { Extrato } \\
\text { etanólico }\end{array}$ \\
\hline Inverno & 0,74 & 0,21 & 0,89 & 4,90 \\
Primavera & 0,52 & 0,27 & 0,75 & 4,42 \\
Verão & 0,64 & 0,22 & 0,66 & 3,53 \\
Outono & 0,63 & 0,43 & 0,81 & 4,82 \\
\hline
\end{tabular}


observados com os extratos etanólicos de A. arborescens. Por outro lado, os baixos teores de açúcares encontrados nos extratos clorofórmicos indicam que estes compostos pouco contribuíram para a ação fitotóxica desses extratos.

\section{Referências bibliográficas}

Ali, M.I.A.; Shalaby, N.M.M.; Elgamal, M.H.A. \& Mousa, A.S.M. 1999. Antifungical effects of different plant extracts and their major components of selected Aloe species. Phytotherapy Research 13: 401-407.

Almeida, F.S. 1988. A alelopatia das plantas. Londrina, Ed. IAPAR.

Alves, S.M.; Muller, A.H. \& Souza Filho, A.P.S. 2002. Alelopatia e a produção de biodefensivos agrícolas. Pp. 205-260. In: A.P.S. Souza Filho, \& S.M. Alves (eds.). Alelopatia. Princípios básicos e aspectos gerais. Belém, Embrapa.

Alves, S.M. \& Santos, L.S. 2002. Natureza química dos agentes alelopáticos. Pp. 25-48. In: A.P.S. Souza Filho \& S.M. Alves (eds.). Alelopatia. Princípios básicos e aspectos gerais. Belém, Embrapa.

Beaumont, J.; Reynolds, T. \& Vaughan, J.G. 1984. Homonataloin in Aloe species. Planta Medica 50: 505-508.

Beppu, H.; Nagamura, Y. \& Fujita, K. 1993. Hypoglycaemic and antidiabetic effects in mice of Aloe arborescens Miller var. natalensis Berger. Phytotherapy Research 7: 37-42.

Beppu, H.; Kawai, K.; Shimpo, K.; Chihara, T.; Tamai, I.; Ida, C.; Ueda, M. \& Kuzuya, H. 2004. Studies on the components of Aloe arborescens from Japan - monthly variation and differences due to part and position of the leaf. Biochemical Systematics and Ecology 32: 783-795.

Bernard, C.B.; Krishnamurty, H.G.; Chauret, D.; Durst, T.; Philogene, B.J.R.; Sanchez-Vindas, P.; Hasbun, C.; Poveda, L.; San Roman, L. \& Arnason, J.T. 1995. Insecticidal defenses of Piperaceae from the neotropics. Journal of Chemical Ecology 21: 801-815.

Costa, F. 2002. Farmacognosia Lisboa, Fundação Calouste Gulbekian.

De Scisciolo, B.; Leopold, D.J. \& Walton, D.C. 1990. Seasonal patterns of juglone in soil beneath Juglans nigra (black walnut) and influence of J. nigra on understory vegetation. Journal of Chemical Ecology 16: 1111-1130.

Dubois, M.; Gilles, K.A.; Hamilton, J.K.; Rebes, P.A. \& Smith, F. 1956. Colorimetric method for determination of sugars and related substances. Analytical Chemistry 28: 350-356.

Einhellig, F.A. 1995. Allelopathy: current status and future goals. Pp. 1-25. In: K.M.M. Inderjit; Darkshini \& F.A. Einhellig (eds.). Allelopathy: organisms, processes and applications. Washington, American Chemical Society.

Einhellig, F.A. 1996. Interactions involving allelopathy in cropping systems. Agronomy Journal 88: 886-893.

Einhellig, F.A. \& Souza, I.F. 1992. Phytotoxicity of sorgoleone found in grain sorghum root exudates. Journal of Chemical Ecology 18: 1-11.

Falkenberg, M.B. 2000. Quinonas. Pp. 545-570. In: C.M.O. Simões; E.P. Schenkel; G. Gossmann; J.C.P. Mello; L.A. Mentz \& P.R. Petrovick (eds.). Farmacognosia da planta ao medicamento. Florianópolis, Editora UFSC.
Feeny, P. 1970. Seasonal changes in oak leaf tannins nutrients as a cause of spring feeding by winter moth caterpillars. Ecology 51: $565-581$.

Ferreira, A.G. 2004. Interferência: competição e alelopatia. Pp. 251-264. In: A.G. Ferreira \& F. Borghetti (eds.). Germinação: do básico ao aplicado. São Paulo, Artmed Editora.

Ferreira, A.G. \& Aqüila, M.E.A. 2000. Alelopatia: uma área emergente da ecofisiologia. Revista Brasileira de Fisiologia Vegetal 12(edição especial): 175-204.

Franco, L.L. 2001. As sensacionais 50 plantas medicinais, campeãs do poder curativo. São Paulo. Editora Lobo Franco.

Fujita, K.; Yamada, Y.; Azuma, K. \& Hirozawa, S. 1978. Effect of leaf extracts of Aloe arborescens Mill subsp. natalensis Berger on growth of Trichophyton mentagrophytes. Antimicrobian Agents Chemotherapy 14: 132-136.

Gatti, A.B.; Perez, S.C.J.G.A. \& Lima, M.I.S. 2004. Atividade alelopática de extratos de Aristolochia esperanzae O. Kuntze na germinação e no crescimento de Lactuca sativa L. e Raphanus sativus L. Acta Botanica Brasilica 18: 459-472.

Gobbo Neto, L. \& Lopes, N.P. 2007. Plantas medicinais: fatores de influência no conteúdo de metabólitos seundários. Química Nova 30: 374-381.

Gutterman, Y. \& Chauser-Volfson, E. 2000. The distribution of the phenolic metabolites barbaloin, aloeresin and aloenin as a peripheral defense strategy in the succulent leaf parts of Aloe arborescens. Biochemical Systematics and Ecology 28: 825-838.

Hejl, A.A.M.; Einhellig, F.A. \& Rasmussen, J.A. 1993. Effect of juglone on growth, photosynthesis, and respiration. Journal of Chemical Ecology 19: 559-568.

Hirata, T. \& Suga, T. 1977. Biologically active constituents of leaves and roots of Aloe arborescens var. natalensis. Zeitschrift für Naturforschung 32: 731-734.

IAG/USP - Instituto de Astronomia, Geofísica e Ciências. Universidade de São Paulo 2005. Dados meteorológicos da cidade de São Paulo. <http://www.iag.usp.br/> (Acessado em: 11/06/2005).

Inderjit; Asakawa, C. \& Dakshini, K.M.M. 1999. Allelopathic potential of Verbesina encelioides root leachate in soil. Canadian Journal of Botany 77: 1419-1424.

Jalal, M.A.F.; Read, D.J. \& Haslam, E. 1982. Phenolic composition and its seasonal variation in Calluna vulgaris. Phytochemistry 21: 1397-1401.

Koshioka, M.; Takino, Y. \& Suzuki, M. 1982. Studies on the evaluation of Aloe arborescens Mill. var. natalensis Berger and Aloe extract (JP IX). International Journal of Crude Drug Research 20: 53-59.

Lin, D.Z.; Dong, Y.J.; Tsuzuki, E.; Sugimoto, Y.; Dong, Y.J. \& Matsuo, T.H. 2004. Allelopathic effects of aqueous Aloe vera leaf extracts on selected crops. Allelopathy Journal 13: 67-74.

Maguire, J.D. 1962. Speed of germination - aid in selection and evaluation for seedling emergence and vigor. Crop Science 1: 176-177.

Maraschin-Silva, F. \& Aqüila, M.E.A. 2006. Potencial alelopático de espécies nativas na germinação e crescimento inicial de Lactuca sativa L. (Asteraceae). Acta Botanica Brasilica 20: 61-69.

Medeiros, A.R.M. \& Lucchesi, A.A. 1993. Efeitos alelopáticos da ervilhaca (Vicia sativa L.) sobre a alface em testes de laboratório. Pesquisa Agropecuária Brasileira 28: 9-14. 
Okamura, N.; Asai, M.; Hine, N. \& Yagi, A. 1996. High-performance liquid chromatographic determination of phenolic compounds in Aloe species. Journal of Chromatography A 746: 225-231.

Oliveira, S.C.C.; Ferreira, A.G. \& Borghetti, F. 2004. Efeito alelopático de folhas de Solanum lycocarpum A.St.-Hil. (Solanaceae) na germinação e crescimento de Sesamum indicum L. (Pedaliaceae) sob diferentes temperaturas. Acta Botanica Brasilica 18: 401-406.

Park, M.K.; Park, J.H.; Kim, N.Y.; Shin, Y.G.; Choi, Y.S.; Lee, J.G.; Kim, K.H. \& Lee, S.K. 1998. Analysis of 13 phenolic compounds in Aloe species by high performance liquid chromatography. Phytochemical Analitical 9: 186-191.

Peres, M.T.L.P.; Silva, L.B.; Faccenda, O. \& Hess, S.C. 2004. Potencial alelopático de espécies de Pteridaceeae (Pteridophyta). Acta Botanica Brasilica 18: 723-730.

Piña-Rodrigues, F.C.M. \& Lopes, B.M. 2001. Potencial alelopático de Mimosa caesalpinaefolia Benth. sobre sementes de Tabebuia Alba (Cham.) Sandw. Floresta e Ambiente 8: 130-136.

Pio Corrêa, M. 1926. Dicionário das Plantas Úteis do Brasil e das Exóticas Cultivadas. Rio Janeiro, Imprensa Nacional.

Reigosa, M.J.; Souto, X.C. \& González, L. 1999. Effect of phenolic compounds on the germination of six weeds species. Plant Growth Regulation 28: 83-88.

Reynolds, T. 1985. Observations on the phytochemistry of the Aloe leaf-exudate compounds. Botanical Journal of the Linnean Society 90: 179-199.

Rice, E.L. 1984. Allelopathy. Florida, Academic Press. Inc.

Saito, H. 1993. Purification of active substances of Aloe arborescens Miller and their biological and phamacological activity. Phytotherapy Research 7: S14-S19.

Santos, S.C.; Costa, W.F.; Batista, F.; Lúcio, R.; Santos, L.R.; Ferri, P.H.; Heleno, P.D.; Ferreira, D. \& Seraphin, J.C. 2006. Seasonal variation in the content of tannins in barks of barbatimão species. Revista Brasileira de Farmacognosia 16: 552-556

Sato, Y.; Ohta, S. \& Shinoda, M. 1990. Studies on chemical protectors against radiation. XXXI. Protection effects of Aloe arborescens on skin injury induced by $\mathrm{X}$-irradiation. Yakugaku Zasshi 110: 876-884.
Sosa, I.H.; González, H.R. \& Mederos, D.M. 2003. Efectos alelopaticos de Aloe vera (L.) N.L. Burm. sobre otras espécies de plantas medicinales em condiciones de laboratório. Revista Cubana de Plantas Medicinales 8.

Stevens, N. 1999. O poder curativo da babosa: Aloe vera. São Paulo, Madras Editora Ltda.

Southwell, I.A. \& Bourke, A. 2001. Seasonal variation in hypericin content of Hypericum perforatum L. Phytochemistry 56: 437-441.

Tang, C.S.; Cai, W.F.; Kohl, K. \& Nishimoto, R.K. 1995. Plant stress and alellopathy. Pp. 142-157. In: K.M.M. Inderjit; F.A. Darkshini \& Einhellig (eds.). Allelopathy: organisms, processes and applications. Washington, American Chemical Society.

Umano, K.; Nakahara, K.; Shoji, A. \& Shibamoto, T. 1999. Aroma chemicals isolated and identified from leaves of Aloe arborescens Mill. var. natalensis Berger. Journal of Agriculture and Food Chemistry 47: 3702-3705.

Viljoen, A.M.; Van Wyk, B.E. \& Newton, L.E. 2001. The occurrence and taxonomic distribution of the anthrones aloin, aloinoside and microdontin in Aloe. Biochemical Systematics and Ecology 29: 53-67.

Yagi, A.; Nishimura, H.; Shida, T. \& Itsuo Nishioka, I. 1986. Structure determination of polysaccharides in Aloe arborescens var. natalensis. Planta Medica 52: 213-218.

Yamamoto, M.; Masui, T.; Sugiyama, K.; Yokota, M.; Nakagomi, K. \& Nakazawa, H. 1991. Anti-inflammatory active constituents of Aloe arborescens. Agricultural and Biological Chemistry 55: 1627-1629.

Yokotani-Tomita, K.; Goto, N.; Kosemura, S.; Yamamura, S. \& Hasegawa, K. 1998. Growth-promoting allelopathic substance exuded from germinating Arabidopsis thaliana seeds. Phytochemistry 47: 1-2.

Waterman, P.G. \& Mole, S. 1994. Analysis of phenolic plant metabolites. London, Blackwell Scientific Publications.

Whittaker, R.H. \& Feeny, P.P. 1971. Allelochmics: chemical interactions between species. Science 171: 757-770. 